\title{
Fulminant hepatic failure in non-Hodgkin's lymphoma
}

\author{
S. BRAUDE \\ M.B., M.R.C.P. \\ B. Portmann \\ M.R.C.Path.
}

\author{
A. E. S. Gimson \\ M.B., M.R.C.P. \\ ROGER WILLIAMS \\ M.D., F.R.C.P.
}

Liver Unit, King's College Hospital and Medical School, Denmark Hill, London SE5

\begin{abstract}
Summary
Two patients with fulminant hepatic failure presenting during the course of non-Hodgkin's lymphoma are described. One patient had no previous history of lymphoma whereas in the other a small bowel lymphoma had recently been diagnosed. Both patients had histological evidence of lymphomatous infiltrate in the liver and no other cause for the fulminant hepatic failure could be found. Neither patient responded to treatment with corticosteroids: the cautious use of combined chemotherapy may be justified.
\end{abstract}

\section{Introduction}

Hepatic involvement in non-Hodgkin's lymphoma is well recognized; the reported incidence in untreated patients varies between $16 \%$ (Kim and Dorfman, 1974) and $22 \%$ (Ferguson et al., 1973) and is higher than that in patients with Hodgkin's disease (5-8\%) staged according to the same criteria. In most patients shown to have lymphomatous infiltration from non-Hodgkin's lymphoma this is clinically obvious with jaundice and hepatomegaly. However, a significant number have no positive clinical findings and normal liver function tests (Bagley et al., 1973). Over the last 30 years there have been a few reports of acute liver failure during the course of Hodgkin's disease (Trewby et al., 1979; Cowan and Trounce, 1973; Fairbank, 1953), but as far as we know this has not been described in nonHodgkin's lymphoma. We describe here two patients in whom this manifestation of liver involvement was observed.

\section{Case reports}

\section{Case 1}

A 24-year-old man was well until 3 weeks before his first admission to hospital when he developed profound anorexia and lethargy. He lost one stone in weight and was admitted to hospital after 3 days of fever and jaundice. Examination revealed pyrexia $\left(40^{\circ} \mathrm{C}\right)$, deep jaundice, and tender hepatomegaly. The prothrombin time was prolonged by $5 \mathrm{sec}$ and there was marked thrombocytopenia $\left(30 \times 10^{9} / 1\right)$. He was given a broad-spectrum antibiotic regimen but remained pyrexial over the next 4 days. In addition, the urine output decreased and the prothrombin time became increasingly prolonged. $\mathrm{He}$ was transferred to this unit on about the 25th day of illness, and neurological examination revealed a drowsy, slightly confused patient with prominent asterixis. The liver was palpable and tender $6 \mathrm{~cm}$ below the right subcostal margin and there was moderate ascites; the spleen was impalpable and no lymphadenopathy was detected.

Initial investigations showed: haemoglobin 9.5 $\mathrm{g} / \mathrm{dl}$; white cell count $5.5 \times 10^{9} / 1(84 \%$ neutrophils); platelets $7 \times 10^{2} / 1$; serum bilirubin $717 \mu \mathrm{mol} / \mathrm{l}$; albumin $24 \mathrm{~g} / 1$; alkaline phosphatase 505 i.u./l; aspartate aminotransferase (AST) 187 i.u./1; urea $37 \cdot 3 \mathrm{mmol} / 1$; creatinine $555 \mu \mathrm{mol} / 1$; prothrombin time $40 \mathrm{sec}$ (control $13 \mathrm{sec}$ ). Negative investigations included tests for hepatitis B surface antigen and antibody, IgM antibodies to hepatitis A virus, and serology for Epstein-Barr virus, cytomegalovirus, and herpes simplex. Serum concentrations of the major immunoglobin sub-classes were normal and blood, ascitic, urine, and sputum cultures were negative. Two iliac crest aspirates yielded plentiful megakaryocytes (no malignant cells were seen) and tests for disseminated intravascular coagulation (including estimation of plasma fibrinogen, thrombin clotting time, and testing for presence of fibrin degradation products) were repeatedly negative.

The patient had persistent pyrexia $\left(38-40^{\circ} \mathrm{C}\right)$ and because the severe thrombocytopenia was thought to have an immune basis, treatment with prednisolone $40 \mathrm{mg}$ daily was started; however, there was no improvement in the platelet count and this was stopped after 4 days. There was steady clinical 


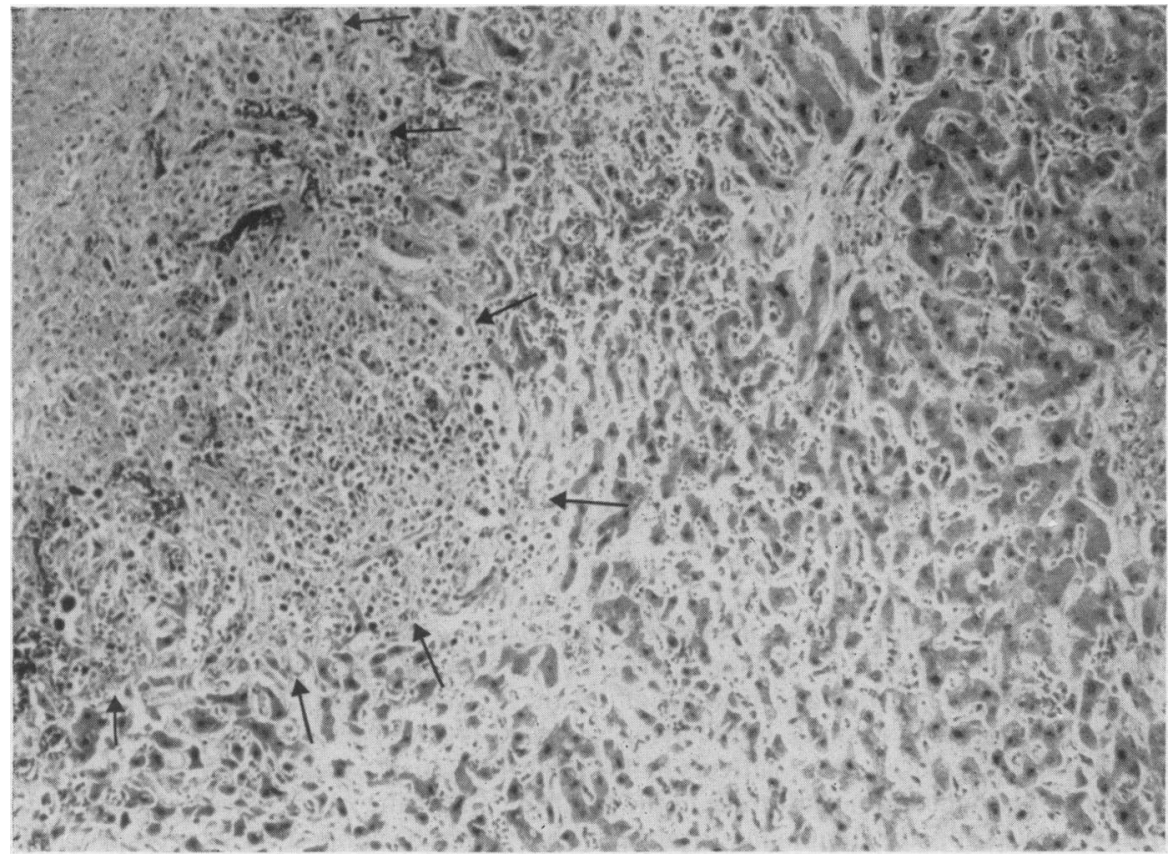

Fig. 1. (Case 1). Demarcation between liver tissue (right) and partly necrotic lymphoma nodule (arrowed) (HE, $\times 120)$.

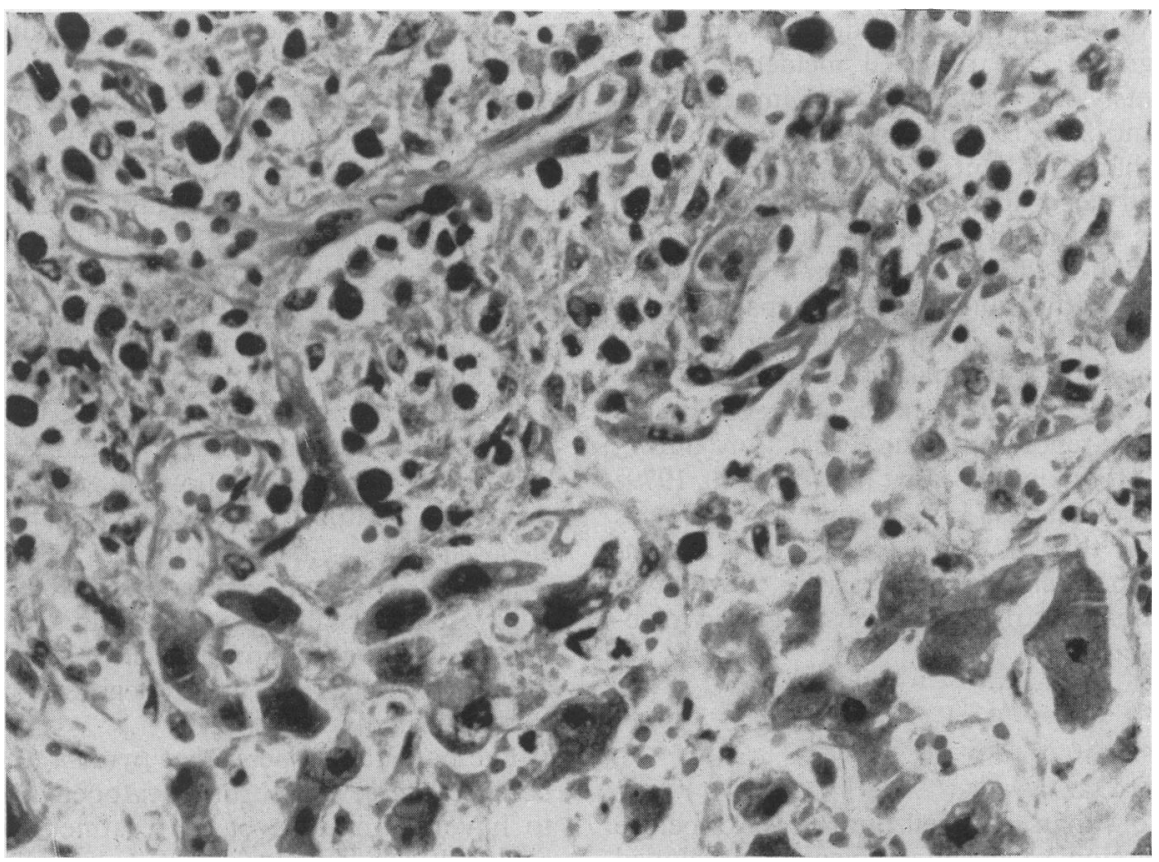

FIG. 2. (Case 1). Liver showing large poorly differentiated lymphoma cells with pyknotic nuclei whose further differentiation is not possible $(\mathrm{HE}, \times 380)$. 
deterioration in liver function, as shown by clinical and biochemical parameters, and in the level of consciousness. Decerebrate posturing and pupillary abnormalities, signs of raised intracranial pressure, were observed terminally, and the patient died 8 days after admission.

At autopsy, the liver and spleen were both enlarged (3018 $\mathrm{g}$ and $700 \mathrm{~g}$ respectively) and showed diffuse infiltration by partly necrotic nodular deposits. There was enlargement of para-aortic lymph nodes above and below the diaphragm and the cut surface of these also showed numerous pale deposits. Histology of liver, spleen and lymph node deposits showed diffuse non-Hodgkin's lymphoma (Figs 1 and 2). Around the deposits, histologically there was a reactive hepatitis with severe Kupffer cell activation and prominent cholestasis but there was no significant hepatic necrosis. The brain was normal on sectioning.

\section{Case 2}

A 40-year-old man with long-standing coeliac disease was admitted to hospital with an exacerbation of central abdominal pain of 5 months duration. At laparotomy a jejunal perforation was found and histological examination of the resected bowel revealed a poorly differentiated non-Hodgkin's lymphoma. Seven days later the patient became jaun- diced and substantially raised serum transaminases (aspartate aminotransferase level 300 i.u./l) were noted. Over the next 48 hours he became more confused and disorientated and was then transferred to this unit. On admission, the patient was drowsy, confused, and responded inappropriately to command but had no localizing neurological signs. He was jaundiced and cachectic but did not have hepatosplenomegaly or palpable lymphadenopathy.

Initial investigations showed: haemoglobin 14.1 $\mathrm{g} / \mathrm{dl}$; white cell count $9.6 \times 10^{9} / 1$; prothrombin time $19 \mathrm{sec}$ (control $13 \mathrm{sec}$ ); albumin $31 \mathrm{~g} / \mathrm{l}$; bilirubin $591 \mu \mathrm{mol} / \mathrm{l}$; alkaline phosphatase 219 i.u./1; aspartate aminotransferase 177 i.u./l; urea $17.4 \mathrm{mmol} / \mathrm{l}$; creatinine $150 \mu \mathrm{mol} / \mathrm{l}$.

An electroencephalogram showed diffuse highvoltage slow waves characteristic of metabolic encephalopathy. Halothane had not been used in the general anaesthesia for laparotomy and neither had blood transfusions been given. Virological studies including hepatitis B surface antigen and antibody, IgM hepatitis A virus antibodies, Epstein-Barr virus, cytomegalovirus, and herpes simplex virus were all negative. Levels of IgG and IgA immunoglobulin subclasses were within normal limits but there was a mild polyclonal increase in $\operatorname{IgM}(2.4 \mathrm{~g} / \mathrm{l})$. Prednisolone $60 \mathrm{mg}$ daily was given as initial treatment for presumed disseminated lymphoma but the patient's

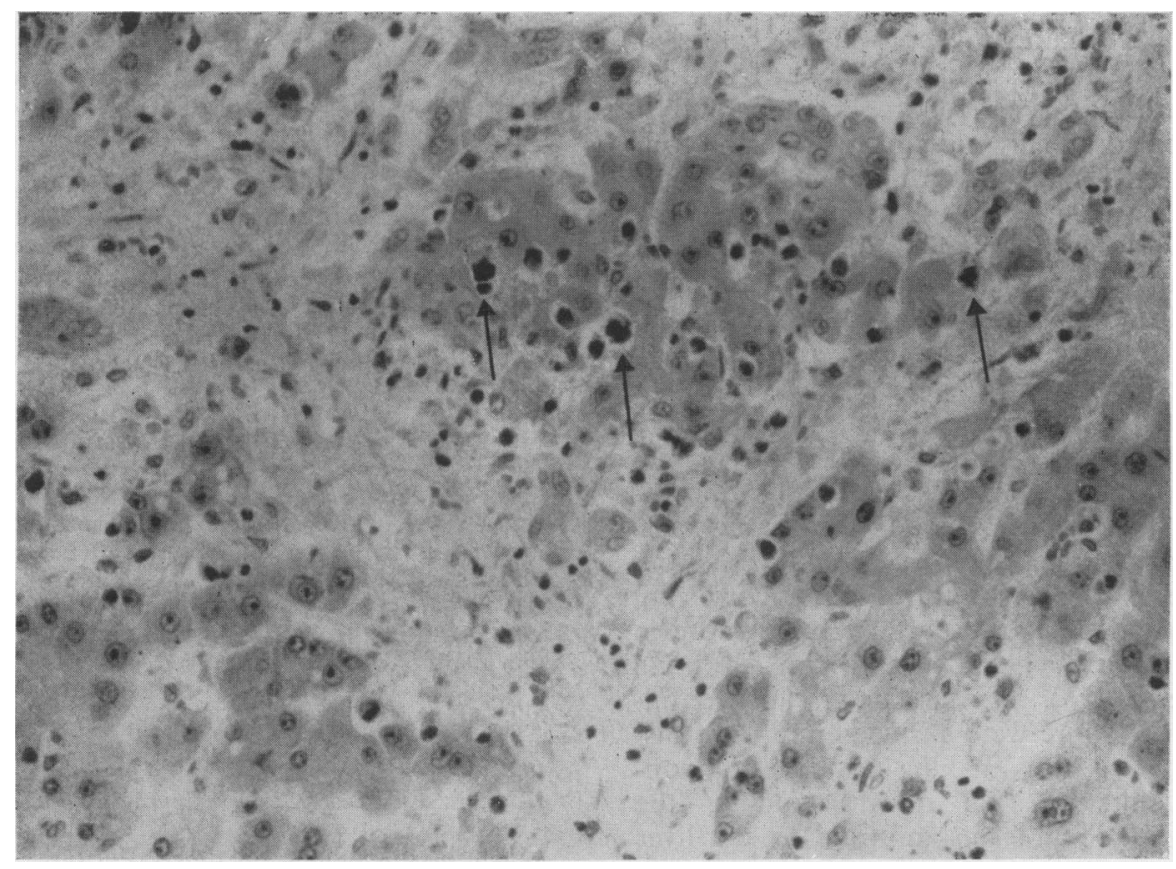

Fig. 3. (Case 2). Liver with scattered atypical cells (arrowed) at margin of necrotic area. 
condition continued to deteriorate with the appearance of signs of grade IV encephalopathy; he died 2 days after admission.

At post-mortem the liver weighed $1530 \mathrm{~g}$ with the cut surface showing diffuse congestive changes only. Histological examination revealed substantial diffuse liver cell necrosis and cholestasis with severe reticulin condensation and early fibrous organisation in keeping with subacute hepatic necrosis.

In addition, there were diffusely scattered clumps of pleomorphic cells showing marked atypia with irregular and intensely hyperchromatic nuclei undergoing frequent mitoses (Fig. 3); this was consistent with non-Hodgkin's lymphoma. Similar appearances were noted in the spleen and through all layers of the small bowel wall. There was no involvement of lymph nodes and the brain was normal on sectioning.

\section{Discussion}

Before developing liver failure, case 1 had jaundice and hepatomegaly but in case 2 the first evidence of hepatic involvement by lymphoma was the presentation with liver failure. At post-mortem in case 1 the liver showed diffuse infiltration by lymphomatous deposits but there was no histological evidence of hepatic necrosis. This, however, is not unusual in fulminant hepatic failure, as, for example, Reye's syndrome (Mowat, 1979) or acute fatty liver of pregnancy (Sherlock, 1981). The evolution of liver failure in this patient fits accepted criteria for fulminant hepatic failure (Trey and Davidson, 1979) with severe encephalopathy and clinical signs of raised intra-cranial pressure. The pathological and clinical features of this patient are most like those of the condition originally described by Scott and Robb-Smith (1939) as 'histiocytic medullary reticulosis'. This is a rare disease in which the cells resemble those seen in non-Hodgkin's histiocytic lymphoma (reticulum cell sarcoma) but the disease is generalized from the outset with systemic symptoms and early involvement of the liver, spleen, lymph nodes, and bone marrow (Kingdon et al., 1970).

In case 2, the liver at autopsy did not show macroscopically well defined tumour deposits; the infiltrate appeared histologically as isolated clumps of cells both in the portal tracts and in the sinusoids. Differentiation into cell type was not possible, but the distribution of the infiltrate with involvement outside the confines of the portal tract is more in keeping with a histiocytic neoplasm (Kim, Dorfman and Rosenberg, 1976). All other known causes of fulminant hepatic failure were excluded and no transfusions were given, thus making acute non-A nonB hepatitis unlikely. This notwithstanding, the relative contribution of this infiltrate to the liver failure is unknown.

Management of patients with fulminant hepatic failure known or strongly suspected to be associated with disseminated lymphoma is difficult. As already discussed, treatment with corticosteroids alone did $\stackrel{\mathbb{Q}}{\odot}$ not alter the course of the liver disease in either $c$ patient. On the other hand there have been cases of $\ddot{\Rightarrow}$ Hodgkin's disease reported in which the liver $\stackrel{5}{+}$ failure after not responding to corticosteroids did $\bar{c}$ remit eventually with combined chemotherapy (Trewby et al., 1979). There may therefore be a $\frac{\omega}{\vec{D}}$ rational basis for more aggressive chemotherapy $\stackrel{\varnothing}{\propto}$ involving a multiple cytotoxic regimen with the proviso that hepatotoxic drugs should be avoided $\vec{\circ}$ and full platelet support instituted if necessary. Finally, any change in consciousness in patients with $\vec{\omega}$ lymphoma should not necessarily be attributed to $\stackrel{\circ}{\circ}$ cerebral spread of the disease, and conversely in $\mathbb{B}$ patients presenting with fulminant hepatic failure, 3 non-Hodgkin's lymphoma has to be added to the list $\mathcal{O}_{\infty}$ of possible causes.

\section{Acknowledgments}

We thank the Departments of Haematology, Chemical Pathology and Virology for their co-operation and Miss Sarah Underhill for editorial assistance.

\section{References}

Bagley Jr, C.M., Thomas, L.B., Johnson, R.E., Chretien, 包 P.B. \& DE ViTA, V.T. (1973) Diagnosis of liver involve- $\vec{c}$ ment by lymphoma: Results in 96 consecutive periton $ळ$ oscopies. Cancer, 31, 840.

Cowan, R. \& Trounce, J.R. (1973) Hodgkin's disease an the liver. Guy's Hospital Reports, 122, 221.

FaIRBANK, W.H.D. (1953) Three atypical cases of Hodgkin? disease presenting with liver failure. Canadian Medical Association Journal, 79, 315.

Ferguson, D.J., Allen, L.W., Grien, I.N.L., Moran, M.E., 응 RAPPAPORT, H. \& UltMAN, J.E. (1973) Surgical experience with staging laparotomy in 125 patients with lymphoma. Archives of Internal Medicine, 131, 356.

KIM, H. \& Dorfman, R.F. (1974) Morphological studies of 84 untreated patients subjected to laparotomy for the staging of non-Hodgkin's lymphoma. Cancer, 33, 657.

KIM, H., Dorfman, R.F. \& Rosenberg, S.A. (1976) Path- $\frac{\bar{\partial}}{2}$ ology of malignant lymphomas in the liver: application in staging. In: Progress in Liver Disease, Volume 5 (Ed. by $\bar{\sigma}$ Popper, H. \& Schaffner, F.), p. 683. Grune and Stratton, New York.

KINGDON, H.S., BARON, H.M., BYRNE, G.E. \& RAPPAPORT, H. (1970) Malignant histiocytosis. Results of combination Vincristine-Prednisone therapy. Annals of Internal Medicine, 72, 705.

MowAT, A.P. (1979) Paediatric liver diseases: medical $D$ aspects. In: Liver and Biliary Disease (Ed by Wright, R., 을 Alberti, K.G.M.M., Karran, S. \& Millward-Sadler, G.H.), N p. 948. W. B. Saunders, London.

ScOTT, R.B. \& Robb-Smith, A.H.T. (1939) Histiocytic N medullary reticulosis. Lancet, ii, 194.

SHERLOCK, S. (1981) Diseases of the Liver and Biliary System, 6th edn, p. 401. Blackwell Scientific Publications, Oxford.

Trewby, P.N., Portmann, B., Brinkley, D.M. \& Williams, R. (1979) Liver disease as presenting manifestation of Hodgkin's disease. Quarterly Journal of Medicine, 48, 137

TreY, C. \& Davidson, C.S. (1970) The management of fulminant hepatic failure. In: Progress in Liver Disease, Vol. 3. (Ed. by Popper, H., \& Schaffner, F.), p. 282. Grune and Stratton, New York. 